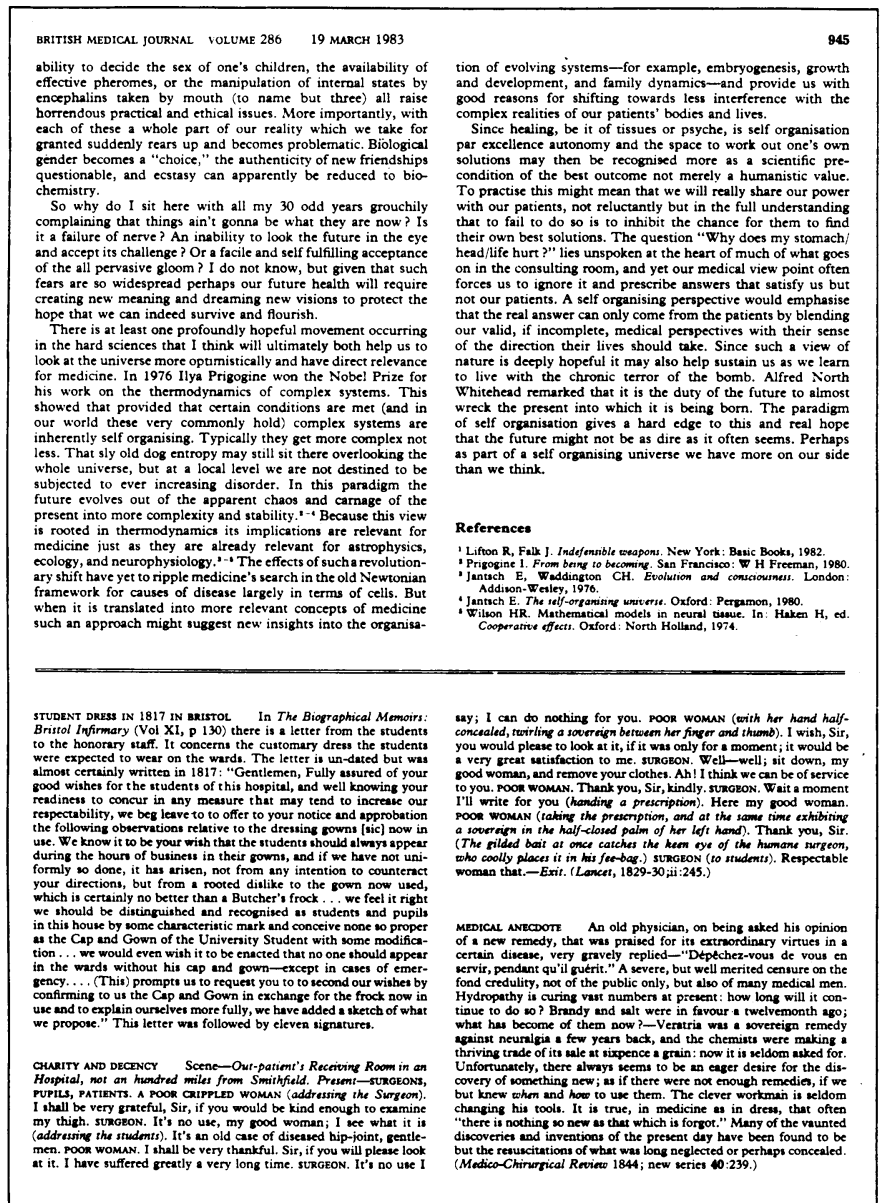

$\begin{array}{llll}946 & \text { BRTISH MEDICAL JOURNAL VOLUMB } 286 & 19 \text { MARCH } 1983\end{array}$

\section{Thinking About the Unthinkable}

\section{Death of a partner}

R J R LEWIS

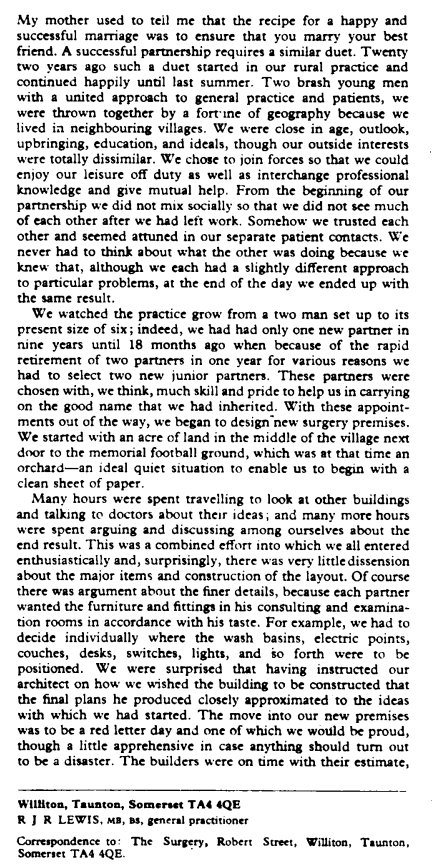

\begin{tabular}{|c|c|}
\hline & \\
\hline \multirow[t]{2}{*}{ 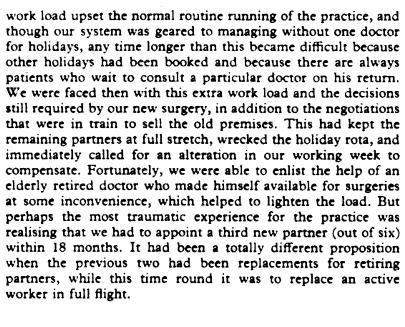 } & 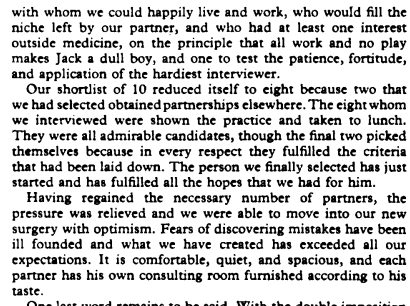 \\
\hline & \\
\hline & \\
\hline 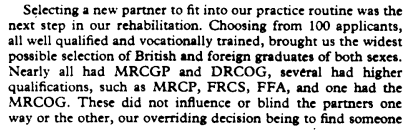 & 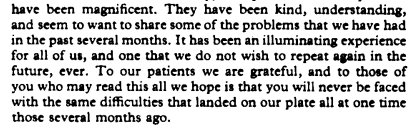 \\
\hline
\end{tabular}

\section{Overlapping with General Practice}

\section{Advice bureau}

BRIDGET GREEVES

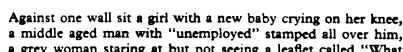

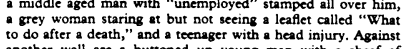

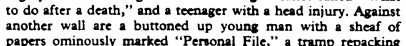

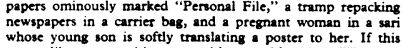

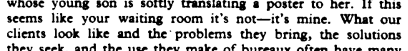

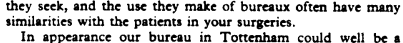

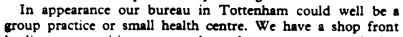

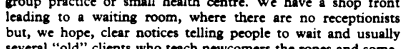

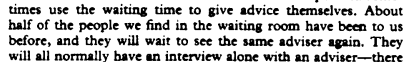

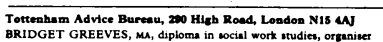

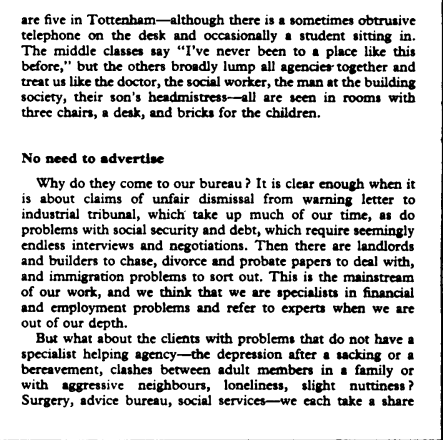

948

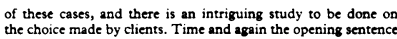

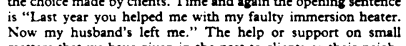

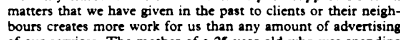
of our services. The mother of 25 year old who was spending
weets in bed with the currains drrwn and the shets over his

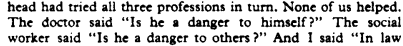

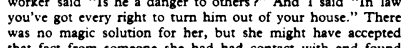

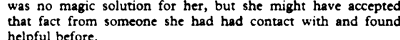

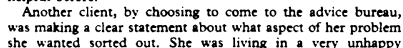

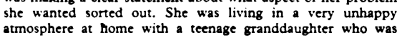

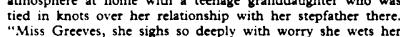

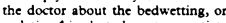

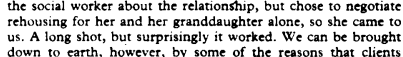
give for their choices. Some have come to the burreau "because
the surgery issn't open in the lunch hour," and one time a

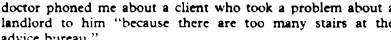

Grey areas

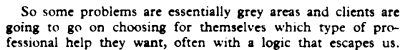

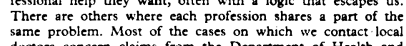

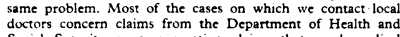

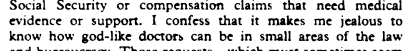

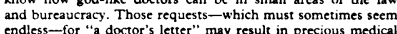

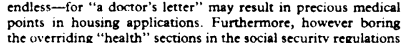

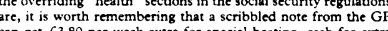

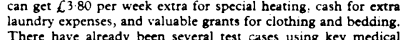

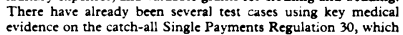
is paid out when it is seren as "he only means by which serious
damage or serrous risk to the heath or saftery of any member of the assessment unit may
is a person, you must note.

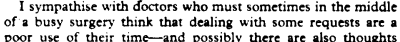

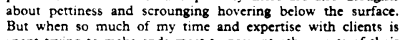

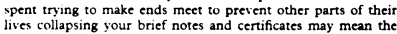

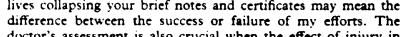

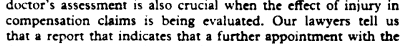

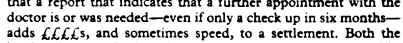

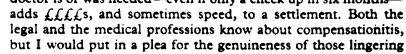

BRITISH MEDICAL JOURNAL VOLUME 28619 MARCH 1983 headaches, the stiffesess, and the rension. Claims for compensa-
tion drag on endlessly, and require going over the seme groun

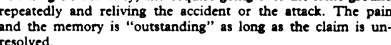
Fit for what?

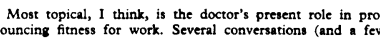

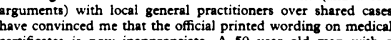

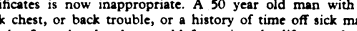

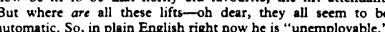

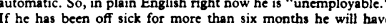

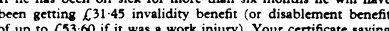
te is " the" moves him straight down to 625 a weck unemploy

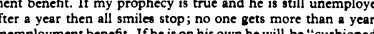

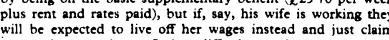

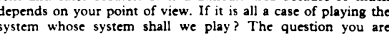
king is, "Is he fit for work?" and the queses on to a

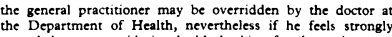
政

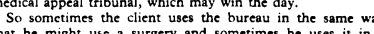

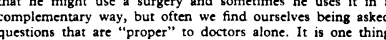

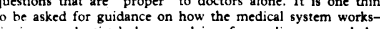
作

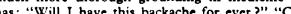
pills as well as Ex Lax?

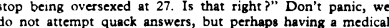
daviser, in the way that we have c a community lauyer to advise

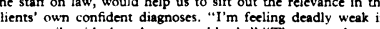

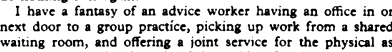

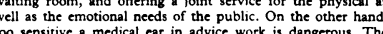

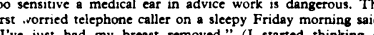

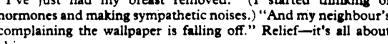
by being on the basic supplementary benefit (C) 25.70 per weed

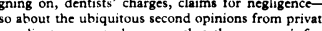

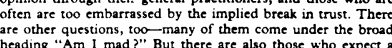

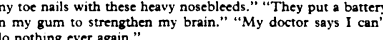

